\title{
NUEVOS AVANCES EN EL CONOCIMIENTO SOBRE EL URBANISMO DE COLONIA PATRICIA CORDVBA EN EL SECTOR OCUPADO POR EL TEMPLO ROMANO
}

\author{
José Luis JIMENEZ SALVADOR \\ Universidad de Valencia \\ Dolores RUIZ LARA \\ Maudilio MORENO ALMENARA \\ Universidad de Córdoba
}

\section{Resumen}

Presentamos los resultados de la excavación arqueológica realizada en 1995 en el solar de la calle María Cristina, situado a espaldas del templo romano de la calle Claudio Marcelo. Esta intervención ha confirmado la existencia de un kardo de la ciudad romana coincidente con la actual calle María Cristina y ha propiciado el descubrimiento de una cloaca de similares características a la recientemente identificada con el kardo maximus.

\section{Summary}

We present the results of an excavation undertaked in 1995 in the plot located of the María Cristina's street, behind the roman temple of the Claudio Marcelo's street. This archaeological research has confirmed the existence of a kardo of the roman city in agreement with the María Cristina's street and also has provided the remains of a sewer with the same type as recently recognized with the kardo maximus.

\section{INTRODUCCION}

Los prometedores resultados obtenidos a raíz de la excavación arqueológica llevada a cabo en 1994 en el solar de la calle María Cristina, situado a espaldas del templo romano (JIMENEZ, RUIZ, 1994, 119-153), (Fig. 1.1 y 1.2), propiciaron la rea- 
lización de una nueva campaña en los primeros meses de 1995 que ha ampliado el conocimiento sobre la evolución urbana en este sector de la parte oriental de la ciudad romana, al haberse recogido nuevas evidencias de la transformación que sufrió el tejido urbano a consecuencia de la construcción del recinto monumental presidido por el templo marmóreo, cuyos vestigios se conservan en el solar que hace esquina entre las calles Claudio Marcelo y Capitulares'.

Como quiera que la descripción pormenorizada de las unidades estratigráficas documentadas en la excavación rebasaría con creces los límites de este artículo, pasaremos directamente a exponer y valorar los datos más significativos que han contribuido a ampliar el conocimiento de la génesis y evolución urbana de este sector de Colonia Patricia Corduba (Fig. 1.3).

\section{LAS CONSTRUCCIONES ANTERIORES A LA EDIFICACIÓN DEL RECINTO RELIGIOSO}

\section{Fase 1}

Se han recuperado nuevas estructuras con las mismas características que las descubiertas en la campaña de 1994 y atribuidas a la primera fase de ocupación de la ciudad. Se trata de cimientos de guijarros de distinto tamaño y trabados con barro, dispuestos directamente sobre el nivel geológico, sobre los que se levantaría un alzado de tapial o adobe, apenas conservado, ya que casi todos los restos corresponden a derrumbes (Fig. 2).

Estos vestigios constructivos revelan una clara planificación urbanística desde el momento en que adoptan un trazado ortogonal con orientaciones alineadas de acuerdo con dos ejes principales que se aproximan bastante al sentido N-S y E-W, delimitando espacios cuadrangulares. La escasa entidad de lo conservado impide elaborar una interpretación segura, apuntándose un posible carácter doméstico. No obstante, la ordenación de estos cimientos permite identificar un muro medianero, orientado en sentido E-W, del que parten varias estructuras alineadas perpendicularmente, sin que en ningún caso lleguen a conservar su entera superficie. Vestigios de un pavimento formado por una delgada capa de arcilla y grava bien compactada se ha recuperado en uno de estos espacios (U. E. 190).

Resulta evidente su situación intra muros, además de constituir los restos más antiguos documentados en este sector de la ciudad romana. La presencia de cerámica campaniense B -que en Corduba se hace patente a partir de mediados del siglo II

' Al igual que la campaña de 1994. la de 1995 quedó contemplada como una actuación previa dentro del Proyecto de intervención sobre los restos del templo romano, incluido en el Converio establecido entre la Junta de Andalucía y el Ayuntamiento de Córdoba. La excavación ha estado codirigida por José Luis Jiménez y Dolores Ruiz Lara, mientras que Maudilio Moreno Almenara ha actuado como arqueólogo de apoyo y responsable de la documentación gráfica. Agradecemos a Angel Ventura la gentileza de permitirnos incluir un dato contenido en su Tesis Doctoral inédita y a Elvira González de Durana su colaboración en la preparación de algunas ilustraciones. 
a. C. (VENTURA MARTINEZ, 1992, 145-150)-en bastante menor proporción que la campaniense $\mathrm{A}$, asociada a ejemplares de ánforas Dressel $1 \mathrm{~A}$, señalan una cronología en las décadas centrales de la segunda mitad del siglo II a. C. Este marco cronológico coincide plenamente con el registrado en la excavación del solar número 23 de la c/ Alfonso XIII (MORENA, 1989, 174-5), muy cerca por tanto de la calle María Cristina, en el que se inscriben una serie de cimentaciones idénticas a las aquí descritas, tanto en su morfología como en su orientación. El mismo comentario puede realizarse en relación con la estructura de habitación fechable en el siglo II a. C. documentada en la Fase I del Corte I, de la excavación en el solar de la «Casa Carbonell» (LEON ET ALII, 1993, II, 163). Esta serie de testimonios que no se reducen a los aquí mencionados y que sin duda se incrementarán a medida que avancen las investigaciones, constituyen la prueba más evidente de la existencia de una trama urbana ortogonal claramente definida desde la primera etapa de la Corduba republicana.

\section{Fase 2}

La campaña de 1995 ha permitido diferenciar una segunda fase también previa a la erección del recinto presidido por el templo. Representa una continuación de la fase anterior, según se desprende de la conservación de estructuras, reparadas en algunos casos y el mantenimiento de diversos espacios, a lo que se suman nuevas construcciones que dejan entrever una consolidación del desarrollo urbano.

La sensación de continuidad resalta como detalle más significativo, ya que en ningún caso se advierte una modificación o alteración de los dos grandes ejes perpendiculares que habían regido la orientación de las fábricas de la fase precedente, reafirmándose la existencia de un planteamiento urbanístico preconcebido.

Se mantienen la mayor parte de las estructuras construidas en la fase anterior, recreciéndolas en algunos casos con mampuestos de caliza (UU.EE. 57 y 250), a la vez que se definen una serie de nuevos espacios. En concreto, ha sido posible diferenciar cuatro ámbitos, todos ellos con pavimento de opus signinum salpicados con teselas de forma aleatoria, separados en dos parejas por el muro medianero de la fase anterior orientado E-W (U.E. 57), (Fig. 3; Lám. 3). Sendos muretes, uno de tapial (U.E. 259) y otro fabricado en opus signinum (U.E. 246), paralelos al muro anterior, dan lugar a las cuatro dependencias de las que ninguna conserva su entera superficie. Ambos muretes conservan su decoración pictórica en color rojo oscuro. Este detalle, unido a la buena factura de los pavimentos en opus signinum, son exponentes de una mayor calidad dentro de su probable funcionalidad doméstica, que se parecen en gran medida, a los cambios documentados en la excavación del solar n. ${ }^{2} 23$ de la calle Alfonso XIII (MORENA, 1989, 174-5). 
Los estratos asociados con las estructuras de esta fase no son abundantes y además de escasa potencia debido, principalmente, a que se superponen sobre los restos de la precedente y por otra parte, se localizan en una zona en la que el estrato geológico aparece a una cota elevada, de modo que no se hizo necesario el empleo de cimientos muy profundos. Estas circunstancias impiden determinar una fecha absoluta con un mínimo de precisión, si bien está claro que representa una etapa post quem respecto de la fase anterior, mientras que los estratos de amortización depositados sobre los pavimentos de opus signinum, exponentes del inicio de la construcción del recinto religioso, constituyen su término ante quem.

Con esta misma fase hay que relacionar la construcción de tres pozos para la captación de agua, uno situado en el ángulo SE del corte 2 (U.E. 153), (Fig. 3; Lám. 4) y otros dos en el corte 3 (U.E. 39 y U.E. 160). El primero (U. E. 153), conserva un encañado de $80-90 \mathrm{~cm}$ de diámetro, realizado con una técnica de notable calidad a base de sillarejos escuadrados y perfectamente trabados (U.E. 152), coronado por dos potentes sillares de caliza (U.E. 264), y rematado por un pavimento de opus signinum (U.E. 158) que rodea el pozo. La superficie del opus signinum muestra la impronta correspondiente al brocal no conservado y su cota se halla sobreelevada unos $50 \mathrm{~cm}$. respecto de la ofrecida por los otros pavimentos de signinum. Los otros dos pozos no conservan tantos detalles, el primero (U.E. 160), presenta un encañado (U.E. 114) con un diámetro aproximado de $130-140 \mathrm{~cm}$, construido con sillares de caliza y fue amortizado con motivo de la erección del recinto religioso; mientras que el segundo (U.E. 39), posee un encañado (U.E. 166), realizado a base de bloques de caliza muy bien trabados. Su parte superior fue objeto de una reparación en época medieval islámica y su estado actual es perfecto hasta el punto de que en la actualidad sigue siendo utilizado.

La presencia de estos pozos asociados con estructuras de carácter doméstico ilustra la manera, probablemente principal, como los habitantes de la Corduba tardorrepublicana resolvían el problema del abastecimiento de agua en un momento en el que todavía no había entrado en funcionamiento el primer acueducto, el Aqua Augusta. Además, la concentración de tres pozos en un área tan reducida, manifiesta la facilidad con que podía accederse al nivel freático del subsuelo, confirmando una idea apuntada recientemente, para justificar la mayor proliferación de pozos frente al menor número de cisternas para la acumulación del agua de lluvia (VENTURA, inédita).

En relación con los efectos devastadores que sufrió Corduba ocasionados por las Guerras Civiles, hay que señalar que no se ha detectado indicio alguno de niveles de incendio, lo que no deja de causar cierta extrañeza, habida cuenta de la magnitud de los destrozos, reflejada por las fuentes escritas (bell. Hisp. 34), cuando en el año 45, después de la batalla de Munda, la ciudad fue pasto de las llamas. Desde luego en es- 
te sector de la ciudad se constata que las construcciones de época imperial mantuvieron los ejes ortogonales de la ocupación republicana.

\section{La cloaca situada detrás del posticum del templo, ¿posible evidencia del decumanus maximus?}

Las labores para completar el descubrimiento de la zona situada inmediatamente detrás del posticum del templo, coincidente con el trazado de la muralla republicana, no han arrojado nuevos datos. La actual red de alcantarillado y el tendido eléctrico han alterado en gran medida las estructuras y estratos antiguos, a la vez que han impedido alcanzar la cota más profunda. Hasta donde ha sido posible excavar no se ha encontrado rastro alguno de la muralla. En cambio, se han recuperado numerosos fragmentos informes de mármol, pertenecientes a la decoración arquitectónica y escultórica del templo y espacio circundante, lo que confirma el expolio de que fueron objeto estas construcciones romanas.

Los resultados negativos en este apartado se han visto compensados con el descubrimiento de los vestigios de una cloaca (Lám. 5 y 6), que ha supuesto la incorporación de un elemento de notable valor para avanzar en el conocimiento del urbanismo de Corduba. Situada detrás del posticum del templo, no ofrece dudas que la construcción del edificio religioso acarreó la pérdida de función de la cloaca, extremo que se ha visto confirmado por algunos escasos materiales recuperados en el sedimento acumulado en su interior, entre los que destacan dos fragmentos informes de Terra Sigillata Italica que remiten a un contexto enmarcado en los primeros decenios del siglo I d. C.

Presenta forma de caja fabricada con 5 bloques de caliza, uno para la base, dos para las paredes y otros dos para la cubierta a doble vertiente. La longitud conservada es de 1,25 m y su altura $1,20 \mathrm{~m}$., mientras que las dimensiones internas son $95 \mathrm{~cm}$ de altura por $65 \mathrm{~cm}$ de ancho. Su fábrica es idéntica a la descubierta en 1991 en la calle Blanco Belmonte, identificada con la cloaca del kardo maximus de la ciudad (VENTURA-CARMONA, 1992, 199-241), mientras que su tamaño es ligeramente inferior.

A pesar de la exigua longitud del tramo excavado, está claro que su orientación E-W corresponde a la de un decumanus de la ciudad romana, sin que pueda afirmarse que se trate del decumanus maximus. En efecto, resulta muy arriesgado prolongar una línea tan corta para comprobar su posible coincidencia con la Puerta de Gallegos, considerada como uno de los extremos del decumanus maximus (IBAÑEZ, 1983, 307-8; STYLOW, 1990, 269), aunque tampoco hay que rechazar de plano esta posibilidad. Primero, por su similitud con la cloaca del kardo maximus y, en segundo lugar, porque esta propuesta plantea un decumanus maximus más lógico que el que tradicionalmente viene situándose en la llamada Puerta de Roma, al Norte del 
templo de la calle Claudio Marcelo y se hace seguir por las calles de la Zapatería y Mármol de Bañuelos -hoy Alfonso XIII- hasta encontrarse con el kardo maximus en San Alvaro, al Sur de la Iglesia de San Miguel, para a continuación buscar la Puerta de Gallegos por un recorrido aún sin aclarar (STYLOW, 1990, 269). De modo que sólo la realización de algún sondeo en la línea teórica que uniría esta cloaca con la Puerta de Gallegos, permitirá despejar esta duda, lo que no impide afirmar que la construcción del templo y pórtico circundante ocasionó su amortización.

A pesar de las reducidas dimensiones del tramo excavado, la pendiente de esta cloaca marcaría una dirección W-E, aprovechando el pronunciado buzamiento que en este punto presenta la topografía de la ciudad, para verter en algún lugar extramuros. Esta hipótesis está respaldada por las cotas ofrecidas por esta estructura, cuya cubierta se encuentra a $113,33 \mathrm{~m}$. s. n. m, mientras que la cloaca situada en la calle María Cristina posee una cota de 114,80 m. s. n. m., lo que supone una diferencia en torno a 1,50 m. No lejos de esta zona, en la calle Alfaros, 18-24, se detectó una cloaca que probablemente desaguaba extramuros por el E (BERMUDEZ ET ALII, 1991, 60). Otro argumento a favor lo constituye la ausencia de estructura: teriores a la construcción del templo y área circundante en el exterior de la mu

\section{LA CONSTRUCCION DEL SECTOR OCCIDENTAL DEL RECINTO RELIGIOSO}

La erección del sector occidental del recinto presidido por el templo acarreó el arrasamiento de las estructuras precedentes. Como exponentes de este proceso, se han identificado varios niveles (UU.EE. 155, 159, 161, 162, 169,183 y 184), que cubrían los pavimentos de opus signinum de la fase anterior. En ellos aparecen mezclados restos procedentes de derrumbes -fragmentos de tegulae, restos de pintura mural con predominio de los colores rojo y negro, nódulos de adobe- con algunos artefactos entre los que se ha recuperado: un borde de TSI de la forma Consp. 27.1, cuya cronología se sitúa entre Tiberio y época flavia (U. E. 184); una base de TSI de la forma Consp. 34.1 con sello CREST, (Oxe-Comfort, 1968, 425), correspondiente al alfarero CHRESTVS con una cronología entre el 10 a. C. y el $30 \mathrm{~d}$. C. y ampliamente atestiguado en Córdoba (García y Bellido, 1970, 81), (U. E. 184) y por último, una base de copa de pie bajo de barniz rojo julio-claudio decorada con cuatro estampillas cuadrangulares formando un cuadrado (U.E. 155). Estas evidencias, aunque escasas, poseen un extraordinario valor, ya que concuerdan con los resultados de las estratigrafías practicadas en los rellenos de cimentación de la cella del templo que sitúan la construcción del edificio religioso a partir de la época del emperador Claudio (JIMENEZ, e. p. $a$ ).

En relación con el espacio situado detrás del posticum del templo, donde se presumía la existencia de un pórtico que delimitase el lado occidental del recinto reli- 
gioso, la campaña de 1994 permitió documentar tres líneas de cimentación paralelas al posticum del templo, orientadas en sentido N-S. (JIMENEZ-RUIZ, 1994, 127), (Fig. 2; Lám. 2). De ellas, las dos más próximas a la fachada posterior del edificio religioso (UU.EE. 45 y 120), corresponden, sin lugar a dudas, al aludido pórtico occidental. A favor de esta interpretación puede argumentarse, por una parte, su adecuación con un modelo de porticus triplex muy difundido en la arquitectura romana y por otra, en la distancia que media entre las dos líneas en torno a los $8 \mathrm{~m}$. que se aproxima bastante a la anchura de los pórticos septentrional y meridional. En cambio, donde sí se advierte una diferencia neta en relación con los otros dos pórticos es en la distancia que media entre el pórtico del lado occidental y la construcción religiosa. Esta alteración del espacio libre entre pórtico y templo pudiera encontrar su justificación en la necesidad de adaptar esta parte del proyecto arquitectónico a un espacio disponible más reducido por la exigencia de quedar integrado en la trama urbana.

En relación con el pórtico occidental, la campaña de 1995 ha completado la recuperación en el Corte 3 de un nuevo tramo correspondiente a la primera línea de cimentación con una longitud de $9 \mathrm{~m}$ por 1,60 m. de anchura (Fig. 4; Lám. 1). Se trata de un cimiento fabricado en opus caementicium cuya potencia excavada oscila en torno a $1,20 \mathrm{~m}$, sobre los que irían colocados los bloques escuadrados que soportarían las columnas del pórtico, de los que no ha quedado resto alguno, ya que fueron desmontados con posterioridad para su reutilización en nuevas construcciones. $\mathrm{Al}$ exterior de este tramo se ha recuperado parte de dos cloacas, una de ellas excavada en la campaña anterior (U.E. 34), con una orientación S-N e igual inclinación, desembocando en una segunda (U.E. 128), que presenta un buzamiento W-E (Fig. 4). Esta sólo se ha exhumado de forma parcial, ya que se le superponen estructuras pertenecientes a fases posteriores, por lo que se ignoran sus dimensiones y su posible conexión con otros ramales. Están construidas con sendas piezas de arenisca y presentan el interior tallado en forma de media caña, siendo las dimensiones de la primera (U.E. 34), $130 \times 60 \mathrm{~cm}$, con una altura aproximada de $25 \mathrm{~cm}$ y una luz interior de $30 \mathrm{~cm}$. Ambas deben formar parte de la red de cloacas de la plaza, encargadas de evacuar las aguas recogidas mediante un canal perimetral al que se conectaban a través de sumideros, y del que se han conservado algunas piezas reutilizadas en construcciones posteriores (U. E. 95).

La presencia de una tercera alineación (U.E. 125) paralela a las dos anteriores y separada de la segunda por una distancia de $4 \mathrm{~m}$., supuso la introducción de un nuevo elemento no constatado hasta entonces en los otros dos pórticos, septentrional y meridional. Como en 1994 sólo había podido exhumarse parcialmente, las nuevas investigaciones han permitido comprobar que su anchura es semejante a la de la segunda cimentación, es decir, entre 1 y $1,10 \mathrm{~m}$., puesto que no es uniforme (Fig. 2). 
En cuanto a la interpretación de su funcionalidad, a la conclusión de la campaña de 1994, se planteó la hipótesis de su pertenencia a una línea de pórtico abierto a una calle que de acuerdo con la orientación, correspondería a un kardo minor que habría quedado perpetuado en el trazado de la actual calle María Cristina (JIMENEZ-RUIZ, 1994, 128). Por otra parte, la existencia de una cimentación realizada con idéntica técnica constructiva y orientada E-W que actuaba como elemento de unión entre la segunda y tercera alineaciones (U.E. 122), (Fig. 2), llevó a interpretarla como un muro de separación de dos tabernae que formarían parte de una hilera dispuesta a lo largo de la calle y a espaldas del pórtico occidental. De cara a determinar la cronología de estas cimentaciones, es indudable que su edificación acarreó la amortización de las construcciones anteriores al quedar éstas por debajo de la cota superior del nuevo conjunto de cimientos.

\section{LA ACTUAL CALLE MARÍA CRISTINA, PERPETUACIÓN DE UN $K A R D O$ DE LA CIUDAD ROMANA}

La necesidad de confirmar o descartar las mencionadas hipótesis motivó la práctica de un sondeo en un tramo de la acera E. y calzada de la calle María Cristina, obteniéndose unos resultados de primer orden (Fig. 2; Lám. 7 y 8). Sin duda, el dato de mayor importancia radica en la constatación de que una cloaca de la actual red de alcantarillado que discurre paralela a la calle María Cristina, es decir, en dirección N$\mathrm{S}$, aproximadamente, está construida aprovechando la parte inferior de una cloaca de fábrica romana (U.E. 223). De entrada, esta evidencia supone la confirmación de la hipótesis apuntada tras la campaña de 1994 (JIMENEZ-RUIZ, 1994, 128-135) en el sentido de que la calle María Cristina habría perpetuado el trazado de un kardo minor. A esta cloaca iba a desaguar otra (UU.EE. 220-221) con una pronunciada inclinación en sentido E-W, construida con dos piezas rectangulares de arenisca con el interior rebajado en forma de media caña, de modo que al superponerse configuran una sección aproximadamente circular (Lám. 8). Su estructura es idéntica a la de la cloaca recuperada en la excavación de los números 4-6 de la calle Blanco Belmonte que desemboca en la cloaca identificada con el kardo maximus y para la que se propone una cronología de finales del siglo I a. C. (VENTURA-CARMONA, 1992, 204).

La parte conservada de esta segunda cloaca se interpone entre dos cimentaciones en opus caementicium, situadas a una distancia de $60-70 \mathrm{~cm}$. de la citada tercera alineación (UU.EE. 213 y 217), (Fig. 4; Lám. 7 y 8). Se trata de dos estructuras cuadrangulares diferentes, que distan entre sí 1,75 y cuyas dimensiones exactas se desconocen, ya que no han podido ser excavadas en su totalidad al introducirse en los perfiles. No obstante, la situada al N (U.E. 217), alcanza 1,70 m. en su lado E-W y su potencia aproximada es de $1 \mathrm{~m}$. Sobre ella se dispone un bloque escuadrado de $65 \mathrm{~cm}$ de anchura por $50 \mathrm{~cm}$ de altura y una longitud excavada de $90 \mathrm{~cm}$. Por su parte, la cimentación localizada al S (U.E. 213), conserva una medida de 1,60 m. en su 
lado E-W y una potencia de $1,35 \mathrm{~m}$. aproximadamente, mostrando también restos de su alzado de bloques escuadrados (U.E. 212). Ambas están ejecutadas siguiendo la misma técnica constructiva utilizada para las cimentaciones del pórtico occidental, aunque la U.E. 213 ofrece un peor grado de conservación que pone en evidencia la baja calidad de la argamasa. Otro dato a tener en cuenta es que se hallan a la misma cota que la segunda y tercera alineaciones, si bien la cimentación localizada al $\mathrm{S}$ se encuentra algo más elevada, entre $25-30 \mathrm{~cm}$, que la situada al $\mathrm{N}$.

La coincidencia en las cotas, así como en la orientación y técnica constructiva apuntan a la posibilidad de que estas dos cimentaciones formasen parte del pórtico oriental del kardo minor ya citado. A favor de esta interpretación estaría el dato recogido por Santos Gener (SANTOS GENER, 1955, 126) y referido al descubrimiento, a comienzos del presente siglo, de una fila de basas de columnas y trozos de fustes que cruzaban la calle Nueva, actual Claudio Marcelo, en la esquina y cruce de esta calle con la del Correo, actual María Cristina. Es muy probable que los elementos ahora recuperados pudieran formar parte del citado pórtico. De este modo, se incorporaría un nuevo testimonio de calle porticada que podría compararse con los restos del pórtico columnado recuperados en el n. 13 de la calle Ramírez de las CasasDeza, que ha sido puesto en relación con la reordenación urbanística que experimentó la ciudad a comienzos del siglo I d. C. (HIDALGO, 1993, 105).

La alteración de la estratigrafía por la propia construcción de la cloaca moderna y por la presencia de conducciones de gas y electricidad, unida a la escasa profundidad a la que aparecen en este sector los estratos de época romana, han impedido determinar la cronología tanto de la cloaca romana que discurre bajo la calle María Cristina, como del tramo conservado de la cloaca que desaguaba en ella. A pesar de estas dificultades, la homogeneidad que preside el conjunto de alineaciones de la parte occidental del recinto religioso, incluidas las dos cimentaciones discontinuas, patente en su idéntica técnica constructiva, así como en la coincidencia de trazado y de cotas, éstas últimas siempre por encima de las construcciones precedentes, demuestra que la edificación del conjunto monumental presidido por un templo entrañó una operación urbanística de mayor envergadura al incluir la reestructuración de la trama viaria situada en su entorno. Es indudable que una operación urbanística de esta magnitud representó todo un hito en el seno de la evolución urbana registrada por la Colonia Patricia Corduba a lo largo del siglo I d. C. (JIMENEZ, 1995, 246).

\section{EL DESMANTELAMIENTO DEL SECTOR OCCIDENTAL DEL RECINTO RELIGIOSO}

Si importantes han sido los datos referidos al urbanismo republicano y altoimperial, no menos relevancia poseen los relativos a las fases posteriores a partir de la pérdida de función del complejo constituido por el templo y pórticos. 
Así como la planta del templo permanece prácticamente íntegra, el sector recuperado del pórtico occidental, situado a espaldas del templo, se encuentra plagado de estructuras de cimentación y numerosos pozos que señalan una prolongada ocupación de este espacio, una vez perdida su función primigenia. A juzgar por la considerable proporción de fragmentos marmóreos reutilizados en diversas fases posteriores, el desmantelamiento de las estructuras del pórtico debió ser total, hasta el punto de que sólo ha permanecido in situ la cimentación en opus caementicium.

La campaña de 1995 ha permitido completar la recuperación de la cloaca descubierta en la campaña precedente dentro del Corte 2 (Fig. 2), que por sus características y cronología, ahora mejor ajustada, evidencia la pérdida de la función original para la que había sido concebido el pórtico occidental. La cloaca se orienta en dirección E-W y está construida a base de bloques de arenisca y caliza -que con toda seguridad fueron reaprovechados de construcciones anteriores- formando una caja (U.E. 43) cuya anchura oscila en torno a $\operatorname{los} 75 \mathrm{~cm}$. Sobre ésta se dispone la cubierta (U.E. 42), con una anchura aproximada de $50 \mathrm{~cm}$, que varía según los tramos y en la que se emplearon materiales de similares características, entre los que se encuentran fragmentos de placas de mármol, un fragmento de fuste estriado que debió pertenecer a las columnas del pórtico, una pieza del canal perimetral de la plaza, fragmentos de losas pertenecientes al pavimento de la misma, etc. (Lám. 9). Para su construcción fue necesario rebajar la primera de las tres cimentaciones de opus caementicium (U.E. 45), correspondiente al apoyo de las columnas, que aparece perfectamente cortada para encajar las paredes de la cloaca (Fig. 2). En cambio, en la presente campaña ha podido comprobarse cómo discurre por debajo de la segunda y tercera líneas de cimentación. La explicación de esta peculiar manera de construcción debe encontrarse, por una parte, en la acusada diferencia de cota del terreno natural, que obligó a disponer de una primera línea de cimentación de más de $2 \mathrm{~m}$. de profundidad como apoyo de las columnas, mientras que la segunda y tercera líneas apenas rebasan el medio metro y, por otra, en la necesaria pendiente que debía describir la cloaca para su correcto funcionamiento.

La reutilización de piezas de mármol -losas y fragmentos de fuste-, así como de otros elementos pertenecientes a la plaza -fragmento de canal perimetral y losas de pavimento-, indican el estado de abandono en que se encontraba el conjunto monumental en el momento en que se lleva a cabo la construcción de esta cloaca.

Esta circunstancia, unida a los artefactos proporcionados por los estratos que la cubren (UU.EE. 32 y 105), entre los que destaca la presencia de TSH Tardía Meridional, llevan a situar su construcción en el siglo IV d. C. Esta cronología queda corroborada por uno de los niveles (U.E. 31), localizados sobre la primera línea de cimentación del pórtico (U.E. 45), caracterizado por la presencia de fragmentos de bloques de arenisca, producto del desmantelamiento de la estructura del pórtico y cuyos 
artefactos -TSA C, TSH Tardía Meridional, imitaciones de Africana, etc.- remiten a un contexto cronológico similar.

Esta etapa viene definida, no sólo por la construcción de la cloaca, sino por una serie de estructuras fabricadas con materiales reaprovechados y cuyo trazado mantiene la orientación ortogonal establecida a partir de la primera ocupación de este sector. Para su alzado se reutilizan los bloques escuadrados del pórtico que se colocan sobre una cimentación de mampuesto (U. E. 84). Se han diferenciado dos muros paralelos (UU.EE. 88 y 118), orientados en sentido E-W y distantes entre sí 2,30 m, así como otro que sigue un trazado N-S (U.E. 84), formando ángulo recto con ambos. El muro 88 conserva una anchura que oscila entre 75 y $80 \mathrm{~cm}$, similar a la del muro 84, en cuya construcción se reutilizó un fragmento escultórico, recuperado en la campaña de 1994 (JIMENEZ-RUIZ, 1994, 129-130; JIMENEZ, 1996, 49-57). Las cimentaciones de todos ellos son de mampuesto, aprovechando materiales de distinta índole, entre los que faltan los fragmentos de mármol, perfectamente visibles en la cimentación del muro 84 (U.E. 278).

La cronología de estas estructuras ha podido determinarse por los restos materiales recuperados en la cimentación del muro 88 (U.E. 91), entre los que se encuentran varios fragmentos de TSA D, TSH Tardía Meridional y una moneda de Constantino II (348-350), todo lo cual permite plantear una fecha comprendida en la segunda mitad del siglo IV, confirmando la cronología propuesta en la campaña de 1994, proporcionada por los artefactos procedentes de las UU.EE. 93 y 104, contemporáneas de este muro (JIMENEZ-RUIZ, 1994, 130).

En el Corte 3 también se han recogido numerosas evidencias del proceso de desmantelamiento y posterior reutilización del pórtico occidental. Se han aislado una serie de muros, orientados de manera aproximada en sentido N-S (UU.EE. 93 y 97 ) y E-W (UU.EE. 28, 96 y 113), como viene siendo característico desde el inicio de la ocupación de este espacio urbano, que con toda probabilidad formarían parte de una estructura doméstica de la que sólo ha podido documentarse una pequeña parte. Para su edificación se han reaprovechado los materiales del conjunto religioso, tanto elementos constructivos, caso de los bloques escuadrados, completos o fragmentados, como piezas marmóreas que formaban parte tanto de la decoración arquitectónica como de la escultórica y que fueron fragmentadas para su utilización en los rellenos de las cimentaciones (Lám. 10). Los muros presentan unos cimientos (UU.EE. 29,111 y 121) a base de guijarros, mampuestos de caliza y mármoles de diverso tipo -fragmentos de fustes, capiteles, cornisas, etc., especialmente evidentes en la cimentación 111-, sobre la que se erige un alzado de sillares de caliza de tamaño dispar, ya que hay algunos completos, como los que integran el muro 113 y otros retallados, formando bloques de inferior tamaño, caso de los muros 96 y 97. 
Los muros 28, 96 y 97 delimitan un espacio que debía estar abierto, si se atiende a la presencia de una canalización (U.E. 95), (Fig. 4), construida con elementos reutilizados de la plaza - piezas de caliza del canal perimetral que servía para la recogida de aguas de los pórticos- y cuya orientación e inclinación en sentido E-NW, permite suponer que iba a desembocar a la cloaca que discurría bajo el kardo perpetuado en la actual calle María Cristina. Su trazado oblícuo quizás obedezca a la presencia de algunas construcciones que interesaba respetar. Esta canalización evacuaría las aguas de este supuesto espacio abierto, uno de cuyos ejes,el definido por la distancia entre los muros 96 y 28 , situados al $\mathrm{N}$ y S, respectivamente, tiene unas dimensiones de $4 \mathrm{~m}$, ignorando si se trata de una pieza cuadrada o rectangular, ya que falta por localizar el muro oriental. Sin embargo, la similitud en las dimensiones de los muros 28 y 97 (4,80 y 4,60 m, respectivamente), permite barajar la hipótesis de una planta cuadrangular (Fig. 5). El pavimento estaba construido con losas reaprovechadas de la plaza, como lo confirma la presencia de alguna de estas piezas dispersas por su superficie (U.E. 94).

Paralelos a los muros 28 y 97 se disponen otros dos paramentos (UU.EE. 113 y 93, respectivamente), separados de ellos por una distancia de $2,5 \mathrm{~m}$., definiendo en conjunto un espacio a modo de galería o corredor que discurre rodeando al espacio abierto, ¿patio?, mencionado más arriba (Fig. 5). Del muro 93 sólo se conserva un pequeño tramo junto al perfil N., ya que fue destruido posteriormente para la construcción de varios pozos localizados en la franja $\mathrm{W}$ del corte. Sin embargo, no existe la menor duda acerca de su adscripción cultural, ya que tanto su técnica constructiva como su posición estratigráfica y los estratos asociados permiten sin ninguna dificultad establecer su cronología y su relación con las restantes estructuras. Por otra parte, la presencia de bloques escuadrados de mayor tamaño en los ángulos formados por los muros 28,96 y 97 , permiten plantear la posibilidad de que actuasen como soportes para columnas.

Estas estructuras son de tipo doméstico y debían formar parte de una casa cuyas dimensiones y distribución son desconocidas, pero que con toda seguridad fue construida mediante el reaprovechamiento de elementos constructivos procedentes del desmantelamiento del pórtico occidental, una vez que este sector del recinto religioso había perdido su función de origen. Los estratos pertenecientes a esta fase (UU.EE. 16, 17, 22 y 24) han proporcionado una gran cantidad de fragmentos de mármol, signo evidente de ese proceso de desmantelamiento. Por lo que se refiere a restos cerámicos, destaca el predominio de TSA C y D, y en especial, la TSH Tardía Meridional que permiten encuadrar este fase dentro del siglo IV d. C.

$\mathrm{El}$ abandono de estas construcciones viene señalado por la presencia de fosas como la U.E. 19, con función de muladares que ha sido colmatadas por rellenos (U.E. 18) con abundante material arqueológico, así como la presencia de estratos de mayor extensión (UU.EE. 82, 84 y 120), formados por sedimentos resultantes de la des- 
composición de materia orgánica -arcillas de tonalidad oscura, con restos de carbón y abundancia de fauna y malacofauna- con gran cantidad de material cerámico y de construcción -fragmentos de tegulae y ladrillos-.

Dentro del conjunto cerámico recuperado destacan por su abundancia las cerámicas toscas tardías, muy características por sus pastas groseras de tonalidad gris oscura, tosco acabado y formas globulares. Asimismo, están presentes la TSA D y TSH Tardía Meridional que trazan un marco cronológico dentro de la primera mitad del siglo V d. C. para el abandono de estas estructuras. Este dato concuerda con la evidencia proporcionada por la excavación realizada en el número 4 de la calle Ambrosio de Morales, distante unos $80 \mathrm{~m}$. al S del recinto del templo de la calle Claudio Marcelo y en la que se ha documentado el abandono de la denominada «Domus II» a finales del siglo IV y 1.a mitad del V d. C. (BERMUDEZ ET ALII, 1991, 57).

La presencia de otras estructuras mínimamente conservadas, tanto en el Corte 2 como en el 3, demuestran las sucesivas reutilizaciones de que fue objeto este sector con fases que pueden fecharse a lo largo de los siglos VIII-XI y XIII-XIV, perpetuándose a lo largo del tiempo hasta alcanzar épocas recientes.

\section{BIBLIOGRAFIA}

BERMUDEZ, J. M.; VENTURA, A.; MARFIL, P. F.; GONZALEZ, C. (1991): "Avance de resultados de la excavación de urgencia en c/ Ambrosio de Morales, 4, recayente a c/ Munda (Córdoba)», Antiquitas, 2, 50-61.

ETTLINGER, E. ET ALII (1990): Conspectus Formarum Terrae Sigillatae Italico Modo Confectae. Materialen zur Römisch-Germanischen Keramik, 10. Bonn.

GARCIA Y BELLIDO, A. (1970): Los hallazgos cerámicos del área del templo romano de Córdoba. Anejos de Archivo Español de Arqueología V. Madrid.

HIDALGO, R. (1993): «Nuevos datos sobre el urbanismo de Colonia Patricia Corduba: excavación arqueológica en la calle Ramírez de las Casas-Deza, 13», Anales de Arqueología Cordobesa, 4, 91-134.

IBAÑEZ, A. (1983): Córdoba hispano-romana. Córdoba.

JIMENEZ, J. L. (1987): «Informe sobre la excavación arqueológica sistemática en el yacimiento denominado templo romano de la calle Claudio Marcelo en Córdoba. Campaña de 1985». AAA '85, 394-397.

—: (1989): «Segunda campaña de excavación arqueológica sistemática, realizada en el yacimiento denominado templo romano de la calle Claudio Marcelo en Córdoba». $A A A$ ' 86, 458-461.

—: (1989-1990): «Arquitectura religiosa romana en Corduba-Colonia Patricia: panorama y perspectivas». Anas, 2-3, 77-86. 
—: (1990a): «Informe sobre la tercera campaña de excavación arqueológica sistemática realizada en el yacimiento denominado templo romano de la calle Claudio Marcelo en Córdoba». AAA' 87, 334-337.

- : (1990b): «Estado actual del conocimiento sobre la arquitectura religiosa romana en Córdoba. Fons Mellaria 1989. Córdoba, 121-140.

—: (1992): «El templo romano de la calle Claudio Marcelo en Córdoba». Cuadernos de Arquitectura Romana, I. 119-132.

- : (1995): «El templo romano de la calle Claudio Marcelo en Córdoba y su importancia dentro del programa monumental de Colonia Patricia durante el Alto Imperio», XIV Congreso Internacional de Arqueología Clásica (Tarragona 1993), Tarragona, 245-251.

- (1996): «Notas sobre un fragmento escultórico procedente del recinto presidido por el templo romano de la calle Claudio Marcelo», II Reunión sobre escultura romana en Hispania, (Tarragona 1995). Tarragona, 49-57.

—-: (e. p. a): «El templo romano de la calle Claudio Marcelo en Córdoba: aspectos cronológicos, urbanísticos y funcionales». Colonia Patricia Corduba: una reflexión arqueológica. (Córdoba, 1993).

—: (e. p. b): «La multiplicación de plazas públicas en la ciudad hispanorromana». Emporiae, 1.

JIMENEZ, J. L.; RUIZ, D. (1994): «Resultados de la excavación arqueológica en el solar de la calle María Cristina en Córdoba, situado a espaldas del templo romano», Anales de Arqueología Cordobesa, 5, 119-153.

KNAPP, R. (1983): Roman Córdoba. University of California Publications. Classical Studies, 30. Berkeley-Los Angeles.

LEON, P.; VENTURA, A.; MARQUEZ, C.; BERMUDEZ, J. M.; VENTURA MARTINEZ, J.J. (1993): «Informe sucinto de resultados de la excavación arqueológica sistemática enn el solar de la Casa Carbonell (Córdoba), 1991", $A A A^{\circ}$ 9I, II, 158-171.

MARTINEZ, F. (1989): «Las cerámicas béticas de imitación tipo Peñaflor: bases para el estudio de un nuevo grupo cerámico de época altoimperial, BEspA, 26, Enero-Junio, 60-65.

MORENA, J. A. (1989): «Intervención arqueológica de urgencia en el solar n. 223 de la calle Alfonso XIII (Córdoba)», $A A A^{\prime}$ '89, 171-175.

ORFILA, M. (1993): «Terra Sigillata Hispánica Tardía Meridional», Archivo Español de Arqueología, 66, 125-147.

OXE, A.; COMFORT, H. (1968): Corpus Vasorum Arretinorum. A Catalogue of Signatures, Shapes and Chronology of Italian Sigillata, Bonn. 
RIBERA, A. (1988-89): «Marcas de Terra Sigillata del Tossal de Manises», Lucentum, VII-VIII, 171-204.

SANTOS GENER, S. de los (1950): «Corduba Marcelli Aedificium». Boletín de la Real Academia de Córdoba, 21, 135-162.

- (1955): Memoria de las excavaciones del Plan Nacional realizadas en Córdoba (1948-1950). Informes y Memorias de la Comisaría General de Excavaciones Arqueológicas, 31. Madrid.

STYLOW, A. U. (1990): «Apuntes sobre el urbanismo de la Corduba romana». W. TRILLMICH y P. ZANKER (eds.): Stadtbild und Ideologie. Die Monumentalisierung hispanischer Städte zwischen Republik und Kaiserzeit, (Madrid 1987). Munich, 259-282.

VENTURA, A. (1991): «Resultados del seguimiento arqueológico en el solar de c/ Angel de Saavedra, n. ${ }^{\circ}$ 10, Córdoba». Anales de Arqueología Cordobesa, 2, 253290.

VENTURA, A. (inédita): Análisis arqueológico de la Córdoba romana a través del ciclo del agua. Tesis Doctoral. Universidad de Córdoba.

VENTURA, A.; CARMONA, S. (1992): «Resultados sucintos de la excavación arqueológica de urgencia en los solares de la calle Blanco Belmonte nos. 4-6 y Ricardo de Montis 1-8, Córdoba. El trazado del Cardo Máximo de la Colonia Patricia Corduba», Anales de Arqueología Cordobesa 3, 199-241.

VENTURA, J. J. (1992): «Cerámica campaniense en la Corduba romana», Anales de Arqueología Cordobesa, 3, 137-170. 

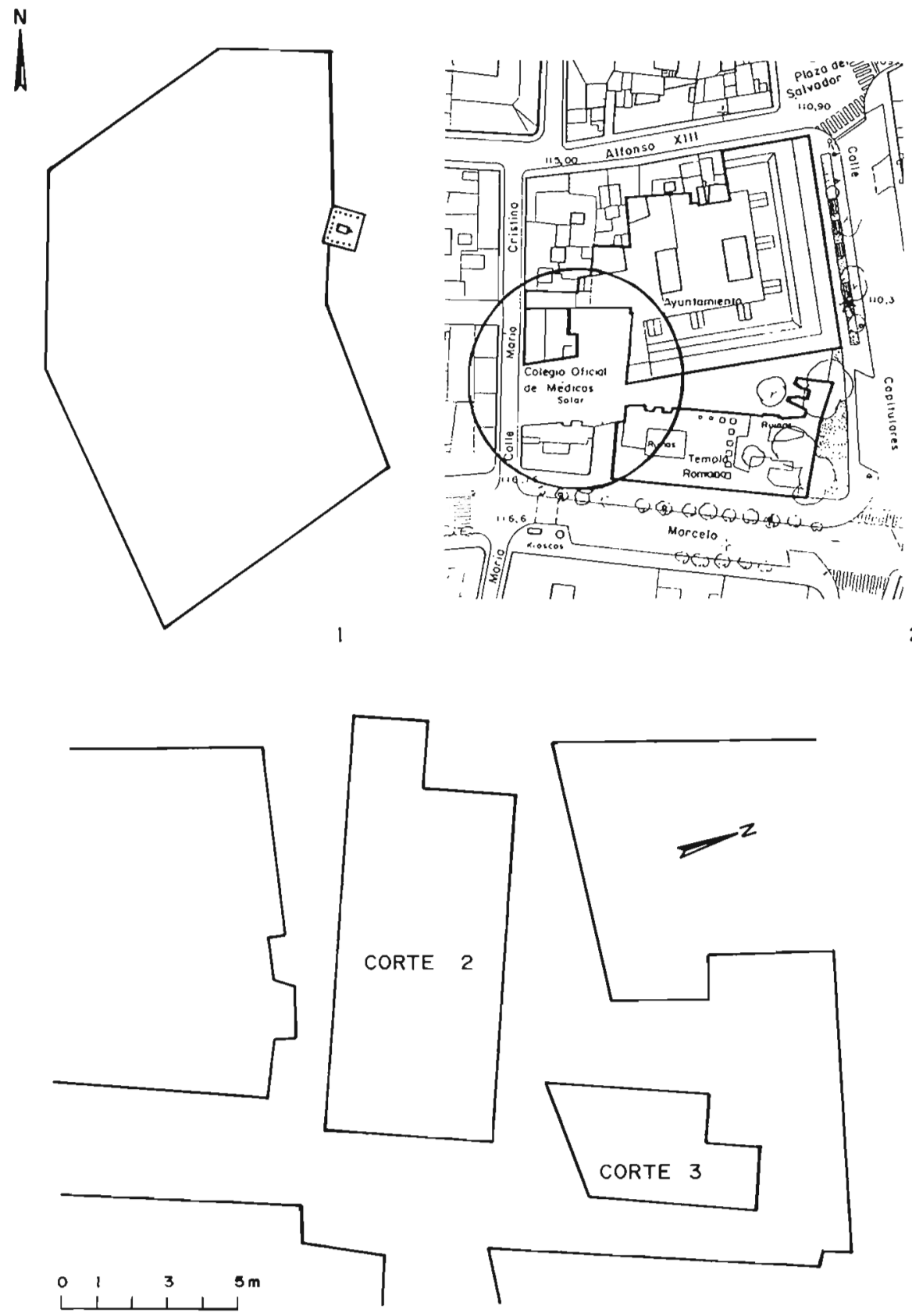

3

Fig. 1.- 1:- Situación del templo dentro del urbanismo de Colonia Patricia Corduba, 2: Localización del solar; 3: Planta general del solar y ubicación de los cortes. 


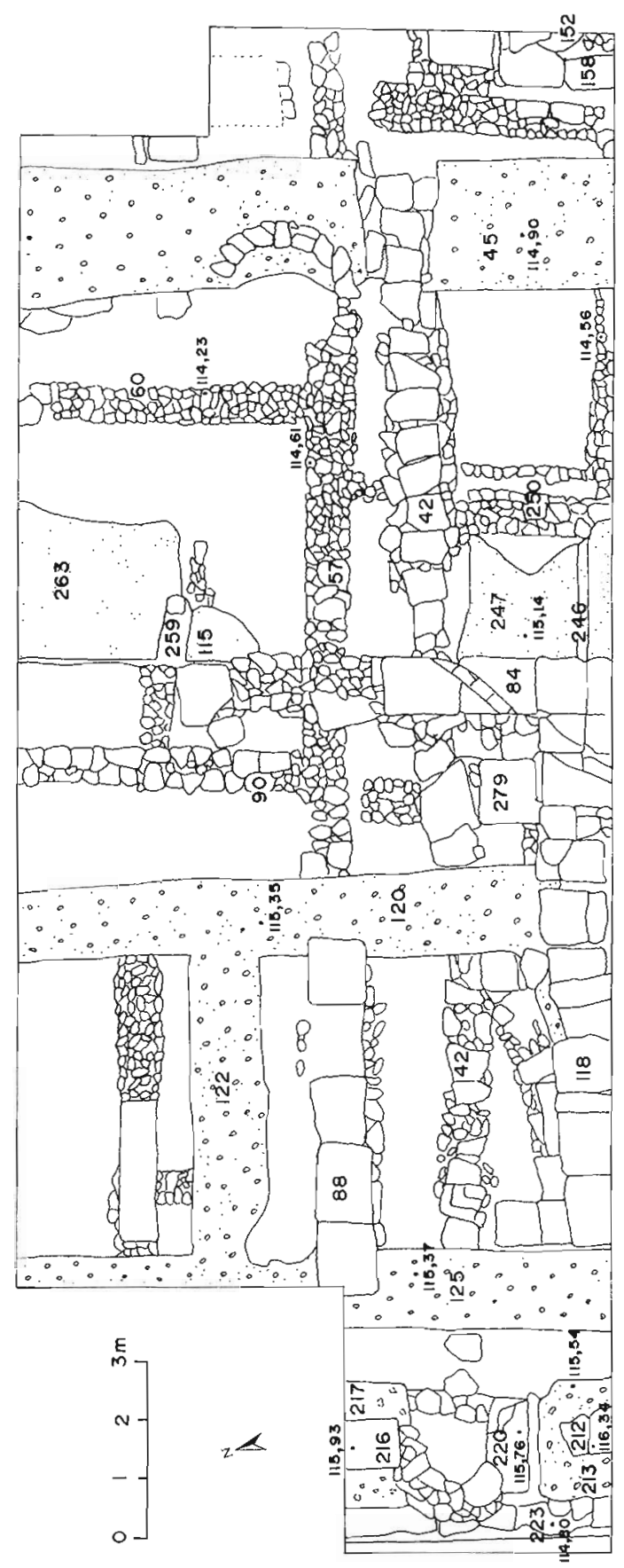

Fig. 2.- Planta general del corte 2. 


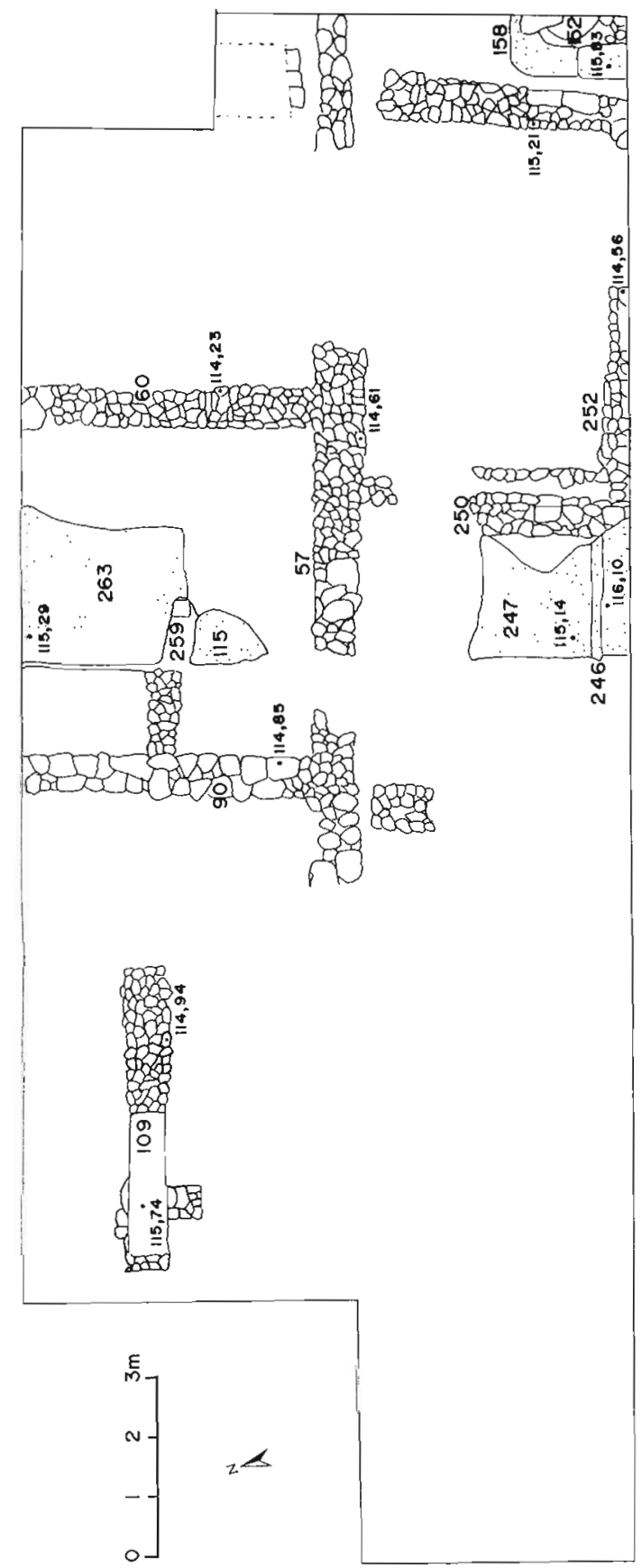

Fig. 3.- Corte 2. Estructuras pertenecientes a la Fase 2. 


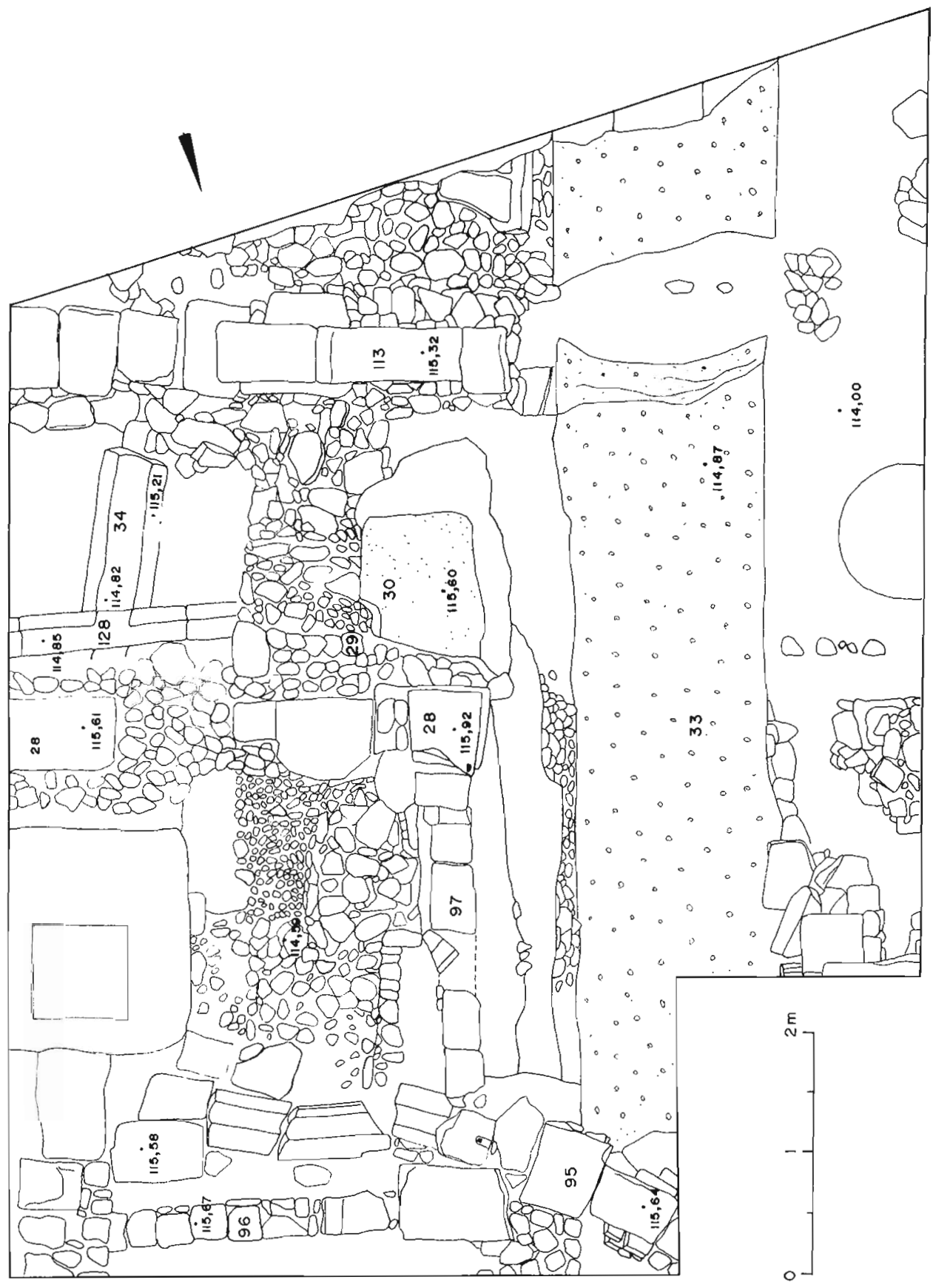

Fig. 4.- Planta general del Corte 3. 


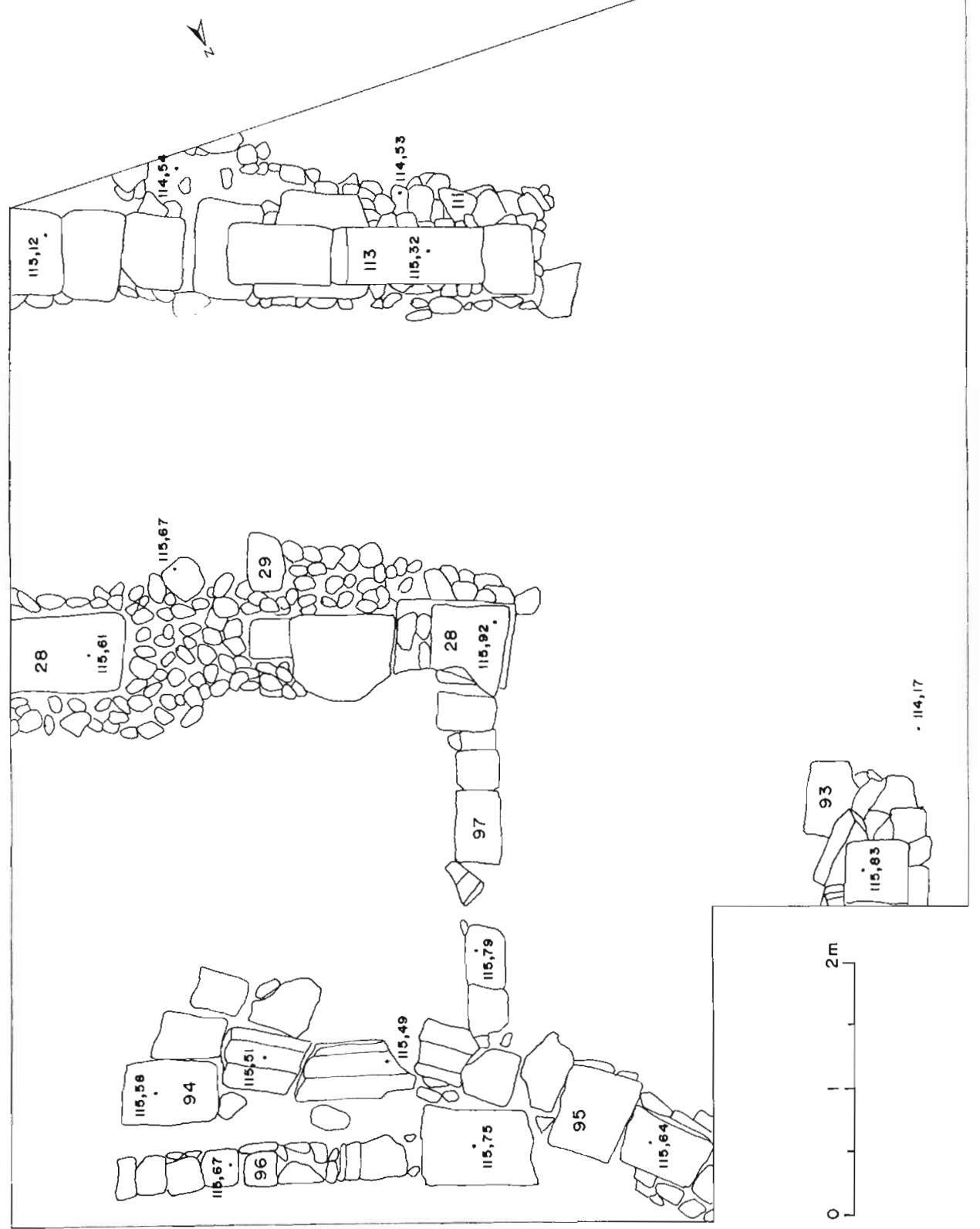

Fig. 5.- Corte 3. Planta del posible patio con corredor. 


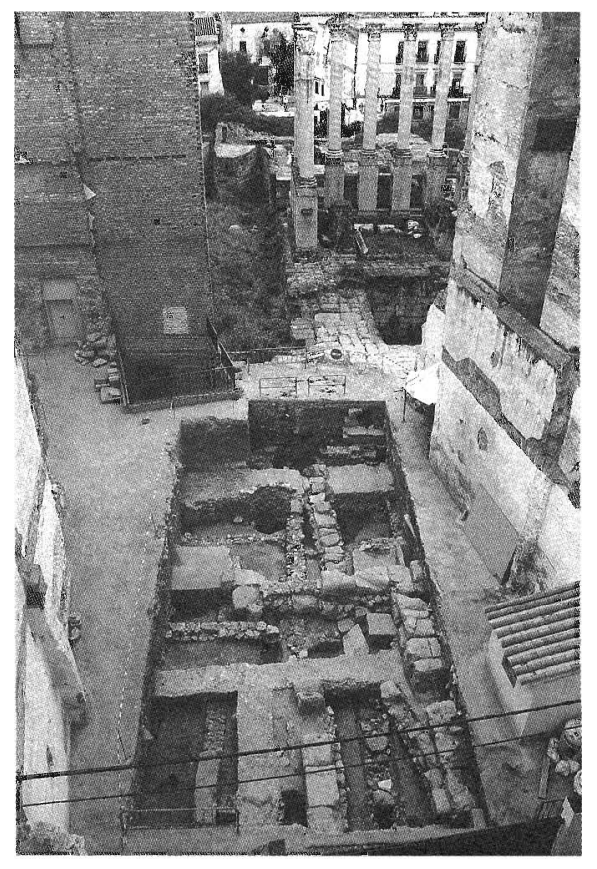

Lám. 1.- Vista general del Corte 2 tomada desde la calle María Cristina.

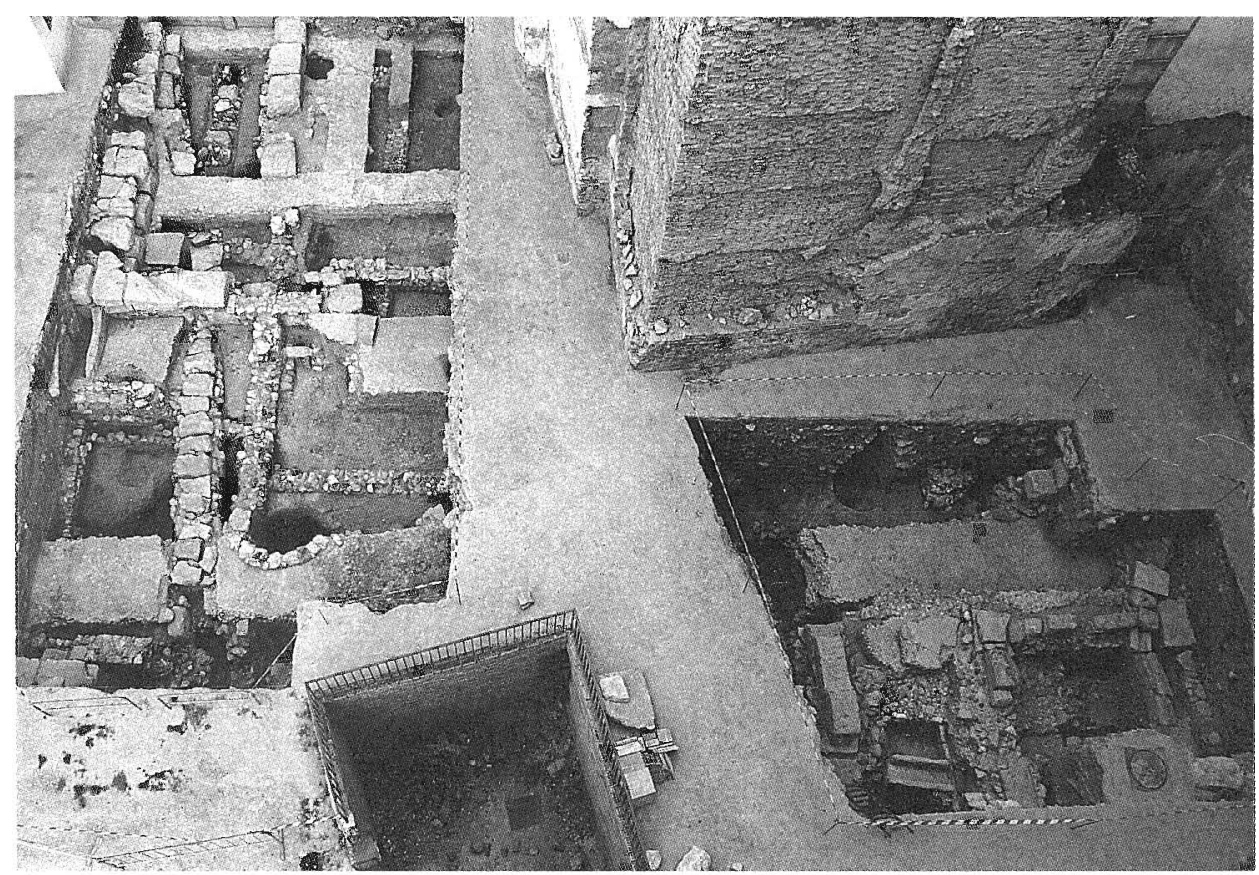

Lám. 2.- Vista de conjunto de los Cortes 2 y 3. 


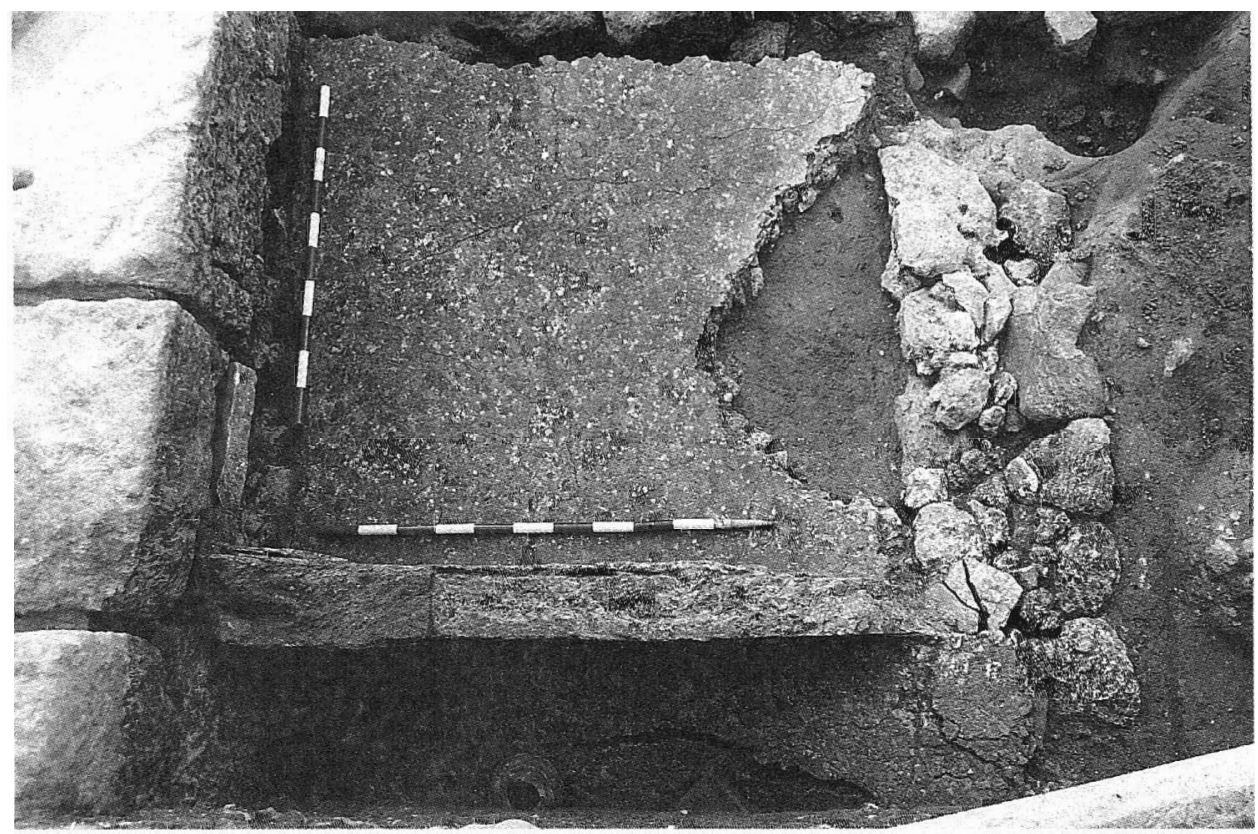

Lám. 3.- Corte 2. Fase 2. Detalle de las dos estancias con pavimento de opus signinum (UU. EE. 247 y 248).

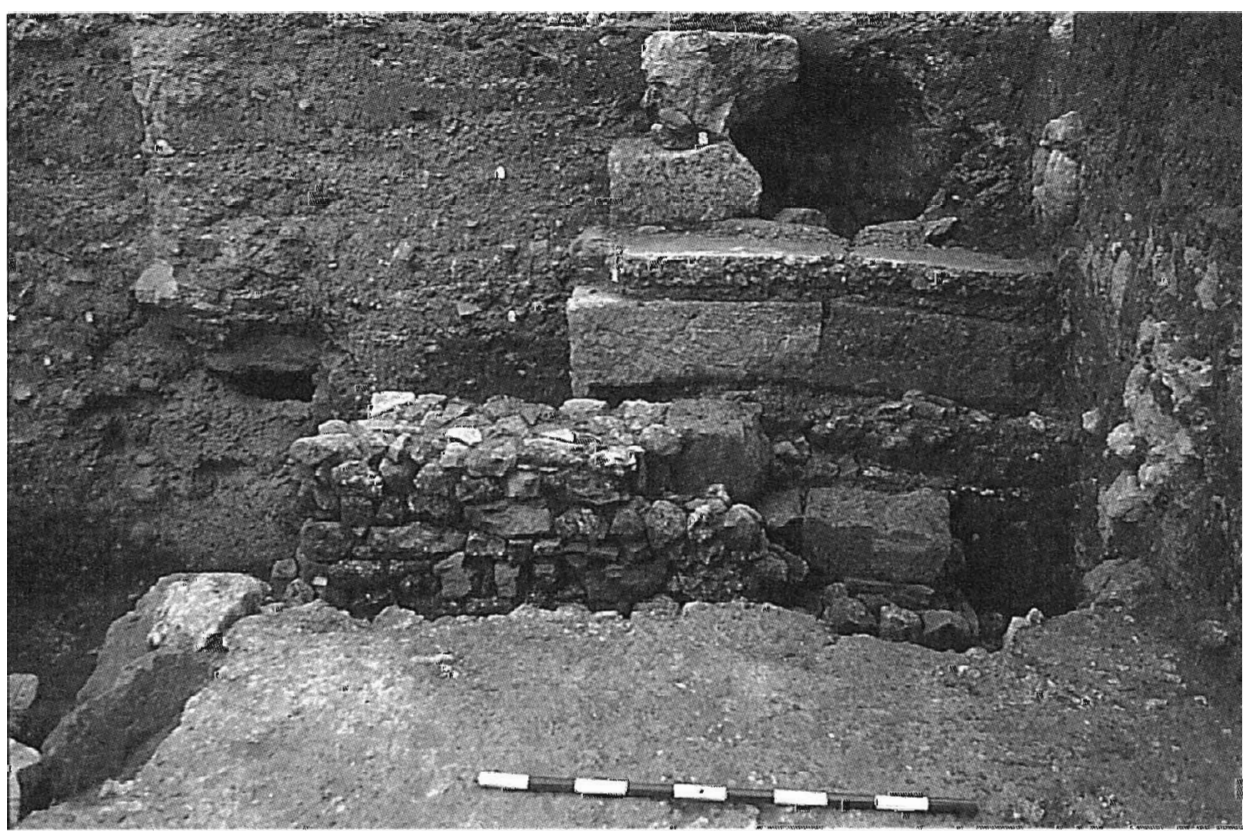

Lám. 4.- Corte 2. Fase 2. Detalle del pozo situado en el ángulo SE. (U.E. 153). 


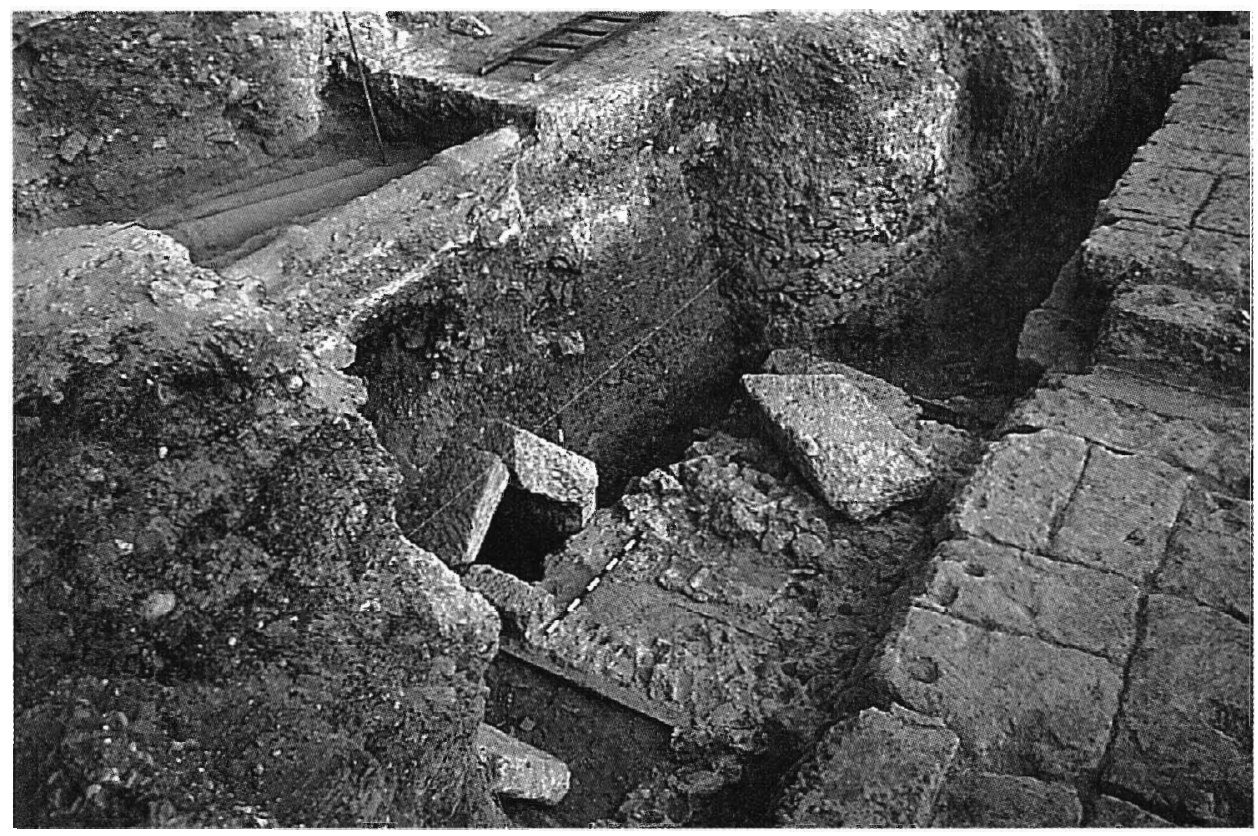

Lám. 5.- Vista de la situación de la cloaca localizada detrás del posticum del templo.

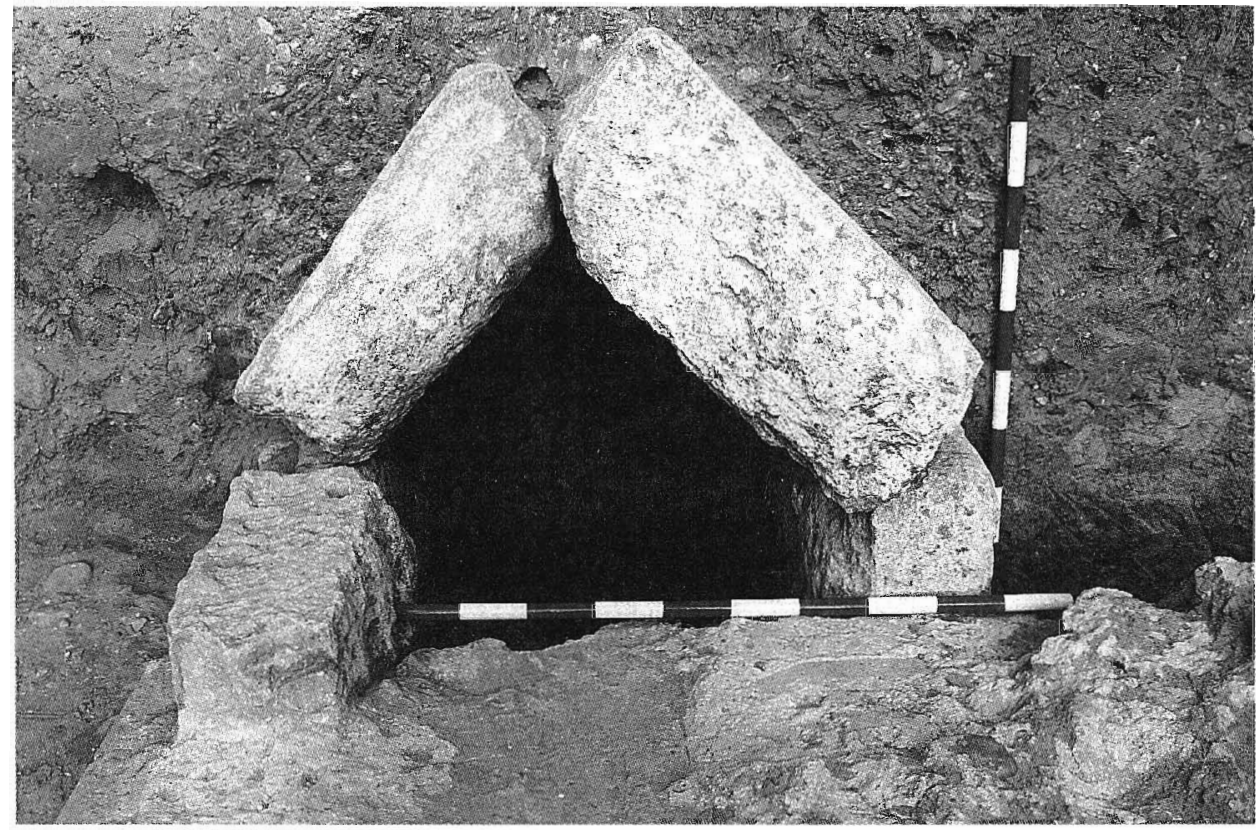

Lám. 6. Detalle de la sección de la cloaca. 


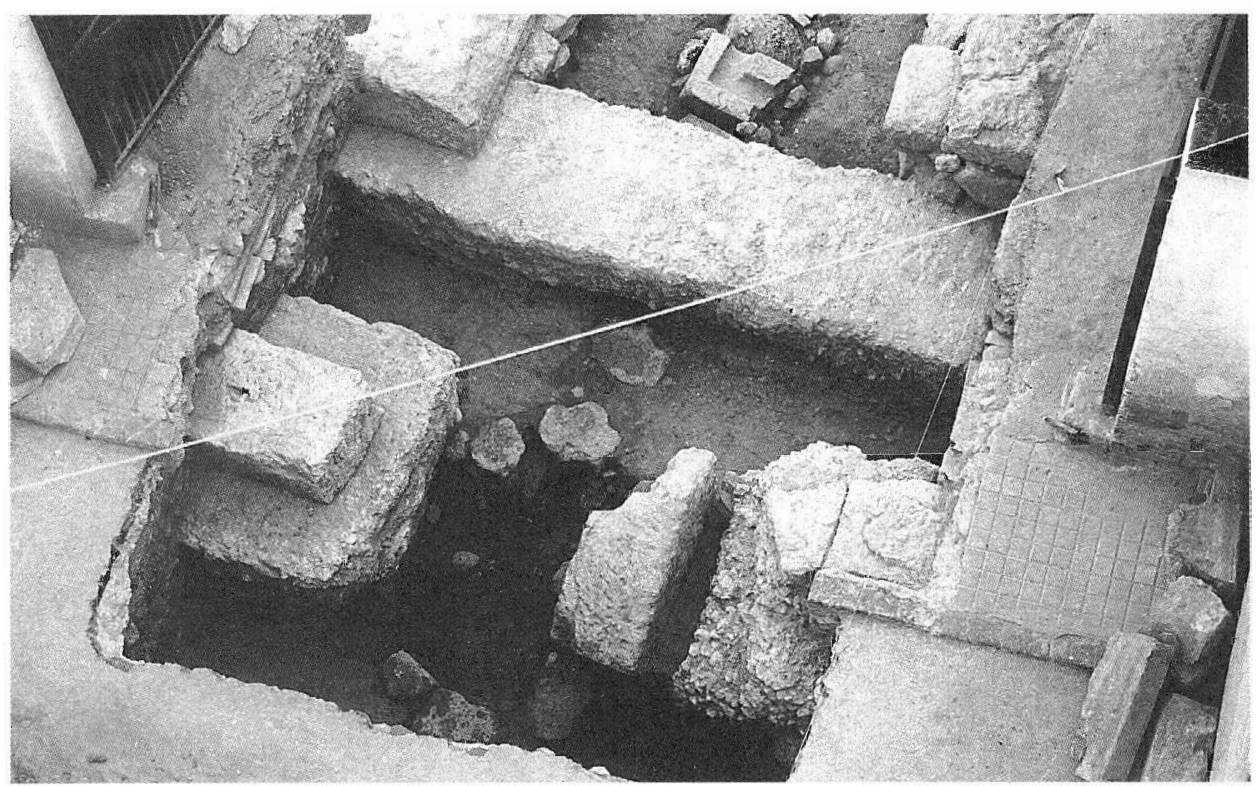

Lám. 7. Corte 2. Vista de la tercera línea de cimentación y de las estructuras localizadas bajo la acera y calzada de la calle María Cristına. A la izquierda. U.E. 217 y a la derecha. U.E. 213. Entre ambas, la cloaca UU.EE. 220-221.

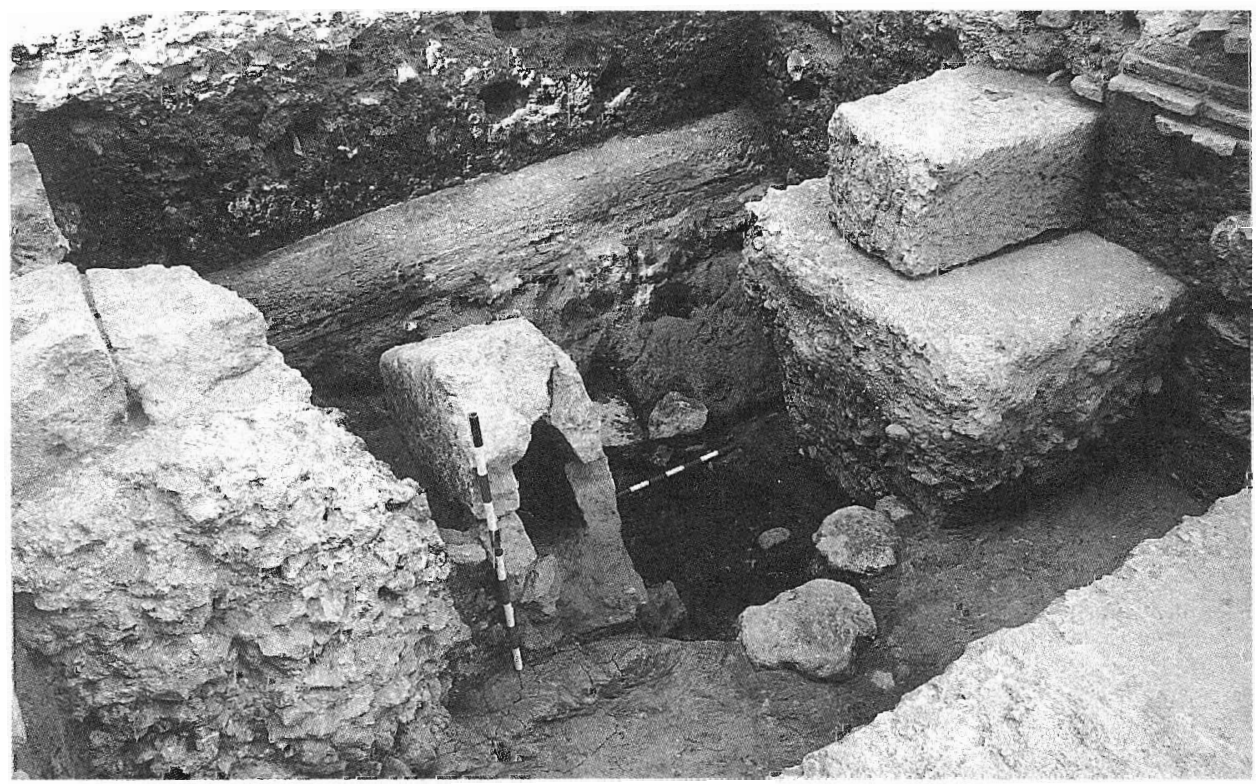

Lám. 8.-Corte 2. Estructuras localızadas bajo la calle María Cristina. Cımentacıones (U.E. 217), a la derecha y U.E. 213, a la izquierda. Cloaca UU.EE. 220-221 entre ambas cımentaciones que desagua en la cloaca U.E. 223. 


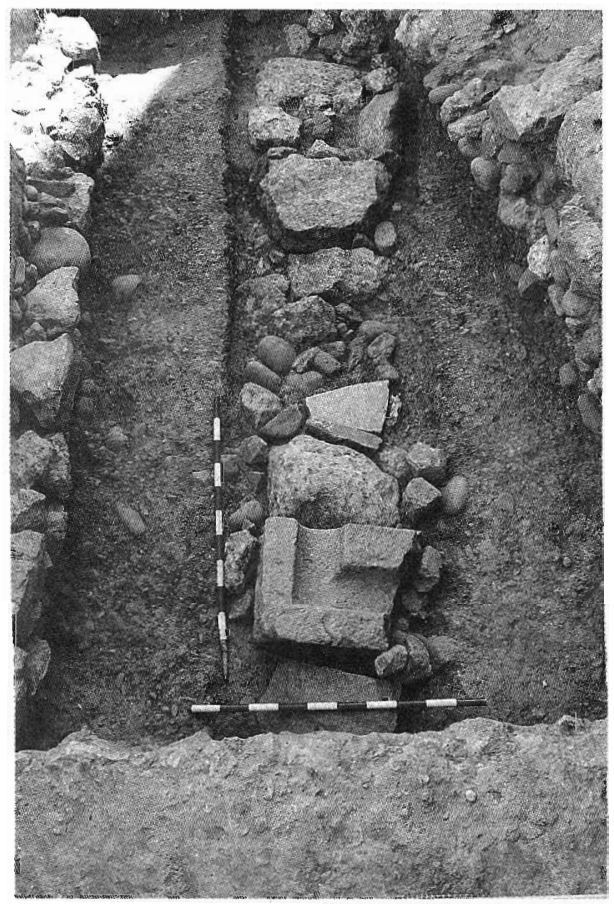

Lám. 9.- Corte 2. Detalle de la cloaca U. E. 42 con un fragmento de canal reutilizado.

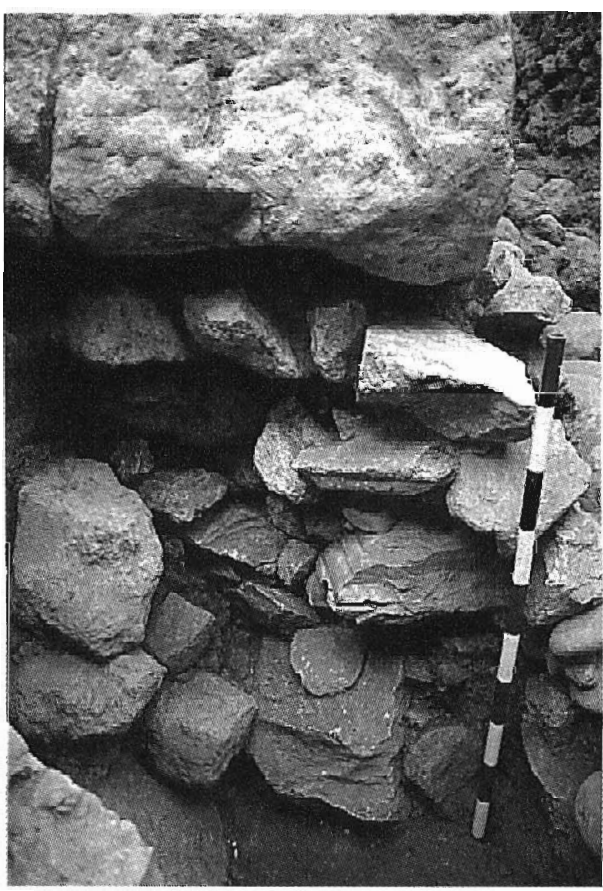

Lám. 10.- Corte 3. Detalle de la cimentación del muro U.E. 113 con elementos reutilizados del recinto religioso. 